\title{
Rancang Bangun Alat Pemanen Energi Listrik Dari Tekanan Mekanik Berbasis Piezoelektrik
}

\author{
Endri Stiawan ${ }^{1}$, Arif Johar Taufiq ${ }^{2}$ \\ Program Studi S1 Teknik Elektro, Universitas Muhammadiyah Purwokerto \\ Fakultas Teknik dan Sains, Universitas Muhammadiyah Purwokerto
}

\section{Kata Kunci : \\ PLTA \\ Piezoelektrik, \\ Lantai, \\ Energi Listrik.}

Informasi Makalah

Dikirim, 19 Agustus 2020

Direvisi, 22 Desember 2020

Diterima, 29 Desember 2020

\begin{abstract}
INTISARI
Energi listrik kini sudah menjadi salah satu kebutuhan pokok saat ini. Semakin banyak jumlah penduduk maka akan semakin besar pula konsumsi listrik yang dibutuhkan. Penelitian ini akan membahas proses pembuatan sebuah alat penghasil listrik dari tekanan mekanik berbasis piezoelektrik yang mengubah energi kinetik dari pijakan manusia untuk menghasilkan energi listrik Mengkompensasi daya yang sangat rendah dari piezoelektrik, agar daya dapat dihasilkan lebih banyak dengan menghubungkan piezoelektrik secara paralel. Piezoelektrik menghasilkan daya listrik dalam arus bolak-balik. Oleh karena itu, agar dapat menyimpan listrik yang dihasilkan piezoelektrik harus diperbaiki oleh sirkuit penyearah. Metode yang digunakan adalah metode eksperimen dimana pijakan yang diberikan pada piezoelektrik bervariasi sehingga menghasilkan tegangan keluaran yang diinginkan. Percobaan yang dilakukan dengan beban manusia seberat $55 \mathrm{~kg}$, $60 \mathrm{~kg}, 75 \mathrm{~kg}$, dan $85 \mathrm{~kg}$ setelah dilakukan pengujian alat penyusunan piezoelektrik secara paralel menghasilkan tegangan keluaran yang didapat sebelum berbeban sebesar 3,54 VDC, 4,80 VDC, 5,21 VDC, dan 6,08 VDC dan setelah berbeban tegangan keluaran yang didapat menjadi 2,15 VDC, 2,16 VDC, 2,19 VDC, dan 2,23 VDC dengan 0,005 mA, 0,006 mA, 0,010 $\mathrm{mA}$ dan $0,027 \mathrm{~mA}$ serta daya yang diperoleh $0,02 \mathrm{~mW}, 0,02 \mathrm{~mW}, 0,02 \mathrm{~mW}$ dan $0,07 \mathrm{~mW}$. Berdasarkan analisis piezoelektrik dapat menghasilkan listrik ketika mendapatkan tekanan oleh pijakan langkah kaki manusia dan sifatnya sementara, oleh karena itu diperlukannya kapasitor sebagai penyimpan.
\end{abstract}

Keywords :

Piezoelectric,

Floor,

Electric Energy

\begin{abstract}
Electrical energy has now become one of the basic needs of today. With more and more population, there will be greater electricity consumption needed. This study will discuss the process of making a power-generating tool from a piezoelectric-based mechanical pressure that transforms the kinetic energi of a human foothold to produce electrical energi. To compensate for the very low power of the piezoelectric, the power can be generated more by connecting the piezoelectric in parallel. Piezoelectric generates electrical power in alternating current. Therefore, in order to be able to save the power produced piezoelectric should be repaired by the rectifier circuit. The method used is the experimental method whereby the footing given to the piezoelectric varies resulting in the desired output voltage. Experiments carried out with the burden of humans weighing $55 \mathrm{~kg}, 60 \mathrm{~kg}, 75 \mathrm{~kg}$, and 85 $\mathrm{kg}$ after the testing of the piezoelectric preparation tools in parallel resulted in a output voltage obtained prior to the load of $3.54 \mathrm{VDC}, 4.80 \mathrm{VDC}, 5.21$ VDC, and 6.08 VDC and after load the output voltage obtained into 2.15 VDC, $2.16 \mathrm{VDC}, 2.19 \mathrm{VDC}$, and $2.23 \mathrm{VDC}$ with $0.005 \mathrm{~mA}, 0.006 \mathrm{~mA}$, $0.010 \mathrm{~mA}$ and $0.027 \mathrm{~mA}$ and acquired power of $0.02 \mathrm{~mW}, 0.02 \mathrm{~mW}, 0.02$ $\mathrm{mW}$ and $0.07 \mathrm{~mW}$. Based on the piezoelectric analysis can generate electricity when gaining pressure by human footrest and its temporary nature, therefore the capacitor is required as a depository.
\end{abstract}




\author{
Korespondensi Penulis : \\ Endri Stiawan \\ Program Studi Teknik Elektro \\ Fakultas Teknik dan Sains, Universitas Muhammadiyah Purwokerto \\ J1. Raya Dukuh Waluh Purwokerto, 53182. \\ Email: endriks173@gmail.com
}

\title{
1. PENDAHULUAN
}

Energi terbarukan adalah suatu energi yang selalu terbaharui dan tidak akan habis dalam waktu yang cukup lama, macam-macam energi terbarukan yang dapat dimanfaatkan untuk pembangkit listrik contohnya adalah material piezoelektrik [1]. Listrik kini menjadi kebutuhan yang sangat penting bagi kebutuhan masyarakat baik itu untuk kebutuhan rumah tangga maupun industri. Banyak tuntunan tak terbatas untuk pasokan energi, namun dengan sumber daya alam yang sangat terbatas. Kini telah menciptakan isu global pada generasi energi masa depan karena menghabiskan sumber daya alam dan menimbulkan efek negatif terhadap lingkungan [2].

Sistem pemanen energi listrik dari piezoelektrik pernah diwujudkan dalam penelitian membuat alat generator piezoelektrik yang dirancang di lantai dengan 9 keping piezoelektrik menggunakan tiga variasi beban manusia menghasilkan tegangan $7-9 \mathrm{mV}$ [3]. Selain itu terdapat jenis penelitian yang sama dengan memanfaatkan putaran kincir 201,3 rpm menghasilkan tegangan maksimal 1,17 VDC [4], ada pula dengan sistem sama dan metode berbeda [5] menggunakan modul LTC3588 selama 2 jam pemakaian dapat mengisi penuh baterai NI-MH 15 mah.

Berdasarkan latar belakang dan hasil penelitian tersebut maka dibuatlah alat "Rancang Bangun Alat Pemanen Energi Listrik dari Tekanan Mekanik Berbasis Piezoelektrik" dengan pemanfaatan pijakan kaki manusia berbeban $55 \mathrm{~kg}, 60 \mathrm{~kg}, 75 \mathrm{~kg}$ dan $85 \mathrm{~kg}$ sehingga menjadi sumber energi listrik yang menggunakan 35 keping piezoelektrik diameter $27 \mathrm{~mm}$ dengan rangkaian komponen dioda bridge dan kapasitor $22 \mu \mathrm{F}$ untuk penyearah tegangan serta penyimpan energi sementara yang dihasilkan dari piezoelektrik agar mendapatkan tegangan yang besar. Penelitian ini dibuat bertujuan untuk menghasilkan listrik sebagai konsumsi daya untuk instrumen elektronik bertenaga kecil.

\section{METODE PENELITIAN}

\subsection{Diagram Blok Alat}

Sistem dimulai dari masukan energi mekanik (getaran) sebagai input dari piezoelektrik. Piezoelektrik berfungsi mengkonversi energi mekanik menjadi energi listrik dan sebaliknya, dengan memanfaatkan piezoelektrik kuat-lemahnya getaran dikonversi menjadi besar-kecilnya tegangan. Selain itu, tegangan akan disearahkan menggunakan penyearah untuk menyimpan energi sementara yang nantinya tegangan keluaran akan menjadi DC, untuk selanjutnya dimanfaatkan menyalakan lampu LED.

Berikut merupakan diagram blok dari sistem pemanen energi listrik dari tekanan berbasis piezoelektrik, dapat dilihat pada Gambar 1 berikut.

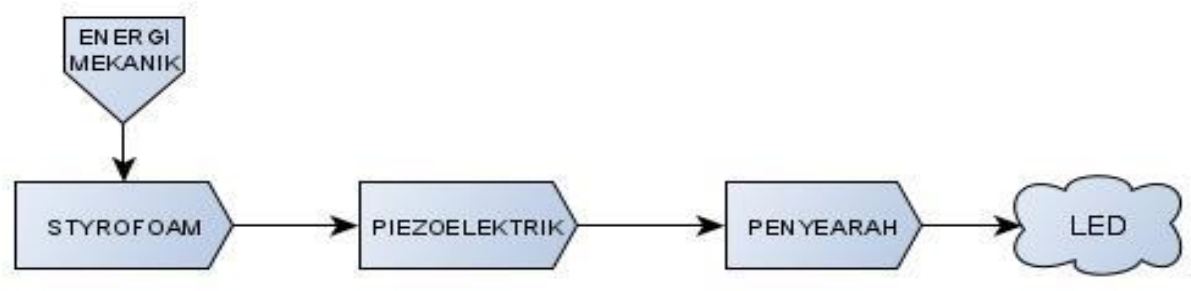

Gambar 1 Diagram Blok Alat 


\subsection{Diagram Alir Sistem}

Sistem akan bekerja mengambil data piezoelektrik berupa getaran yang didapat dari energi mekanik yang diterima oleh piezoelektrik, jika tidak ada data (getaran) yang masuk maka piezoelektrik akan menunggu data untuk diproses. Sebaliknya jika ada data masuk, maka data akan dikonversi menjadi tegangan oleh piezoelektrik. Tegangan output dari piezoelektrik akan disearahkan dan distabilkan. Diagram alir sistem pemanen energi listrik piezoelektrik dapat dilihat pada Gambar 2.

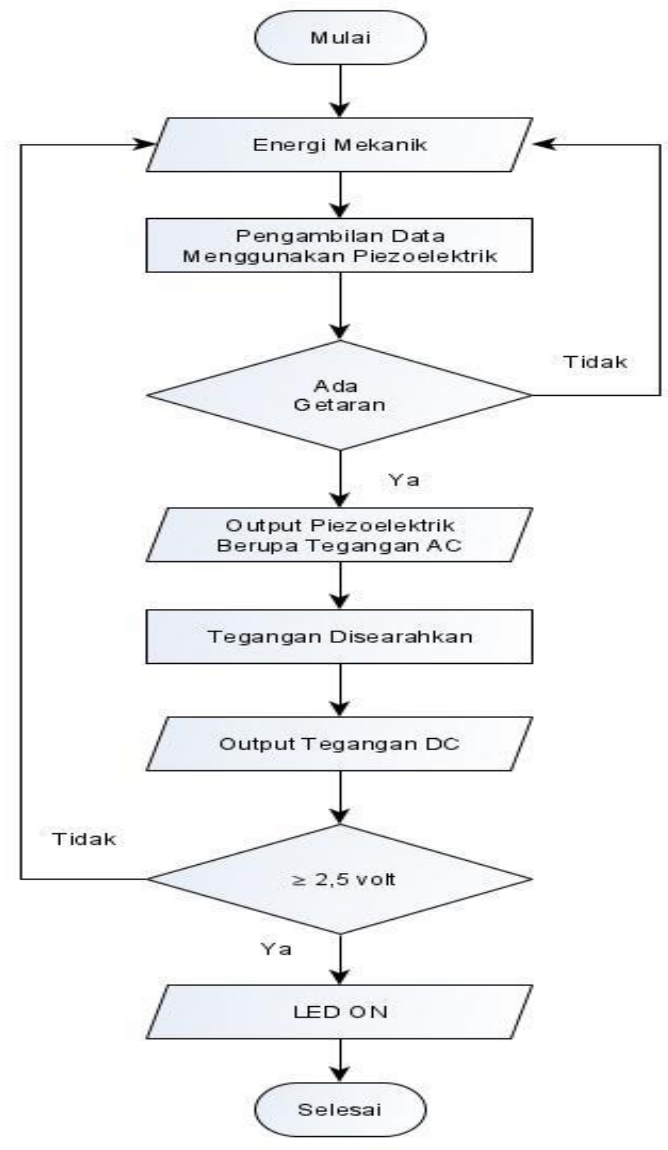

Gambar 2 Diagram Alir Sistem

\subsection{Perancangan Perangkat Keras}

Rangka lantai piezoelektrik berfungsi untuk menempatkan dan menopang kepingan piezoelektrik ketika dipijak sehingga dapat melindungi piezoelektrik dari kerusakan. Desain alat tampak depan memperlihatkan penempatan keping piezoelektrik yang tidak beraturan. Hal ini karena menyesuaikan dari rangka lantai kayu yang telah dibuat supaya mendapatkan tekanan pijakan yang merata sewaktu papan diinjak oleh beban manusia. Desain rangka dapat dilihat pada Gambar 3 berikut.

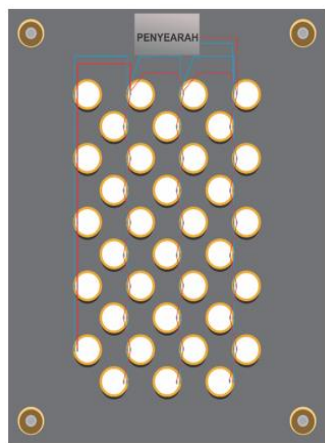

Gambar 3. Desain Rangka Piezoelektrik 


\section{HASIL DAN PEMBAHASAN}

Komponen piezoelektrik sebanyak 35 keping dihubungkan secara paralel agar tegangan keluaran yang keluar dapat lebih stabil, kemudian piezoelektrik dihubungkan seri ke dioda. Hal ini dilakukan agar arus listrik tidak dapat kembali atau menuju ke piezoelektrik yang lainnya, yang mana akan saling mempengaruhi tegangan keluarannya ketika tidak dipasangkan dioda pada rangkaian seri-paralel tersebut. Hasil rangkaian keeping piezoelektrik dapat dilihat pada Gambar 4.

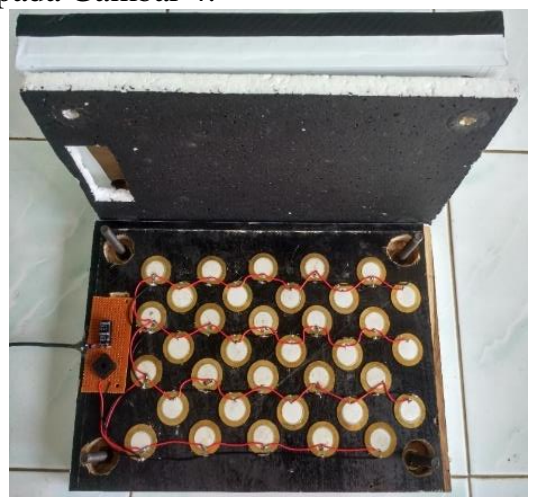

Gambar 4. Rangkaian paralel piezoelektrik

\subsection{Pengujian pada piezoelektrik}

Tabel 1. Hasil pengukuran tegangan piezoelektrik satu persatu dengan pijakan kaki

\begin{tabular}{ccccccc}
$\begin{array}{c}\text { Berat } \\
\text { Manusia }\end{array}$ & $\begin{array}{c}\text { Uji 1 } \\
\text { (VAC) }\end{array}$ & $\begin{array}{c}\text { Uji 2 } \\
\text { (VAC) }\end{array}$ & $\begin{array}{c}\text { Uji 3 } \\
\text { (VAC) }\end{array}$ & $\begin{array}{c}\text { Uji 4 } \\
\text { (VAC) }\end{array}$ & $\begin{array}{c}\text { Uji 5 } \\
\text { (VAC) }\end{array}$ & $\begin{array}{c}\text { Rata-Rata } \\
\text { (VAC) }\end{array}$ \\
\hline $55 \mathrm{~kg}$ & 0,34 & 0,42 & 0,35 & 0,31 & 0,47 & 0,37 \\
$60 \mathrm{~kg}$ & 0,45 & 0,47 & 0,54 & 0,64 & 0,52 & 0,52 \\
$75 \mathrm{~kg}$ & 0,51 & 0,59 & 0,61 & 0,42 & 0,52 & 0,53 \\
$85 \mathrm{~kg}$ & 0,68 & 0,57 & 0,62 & 0,47 & 0,67 & 0,60
\end{tabular}

Dari data Tabel 1 dapat disimpulkan, bahwa dari 35 keping piezoelektrik tersusun paralel tanpa dirangaki dengan penyearah menggunakan variasi pijakan beban manusia $55 \mathrm{~kg}, 60 \mathrm{~kg}, 75 \mathrm{~kg}$, dan $85 \mathrm{~kg}$ ini mendapatkan hasil bahwa semakin bertambah beban manusia nilai tegangan piezoelektrik akan semakin tinggi.

\subsection{Pengujian Tegangan Tanpa Berbeban Dan Penyearah}

Pengukuran output tegangan 35 keping piezoelektrik tersusun secara paralel melalui pemberian penekanan yang sama dengan berat tubuh manusia bervariasi dari $55 \mathrm{~kg}, 60 \mathrm{~kg}, 75 \mathrm{~kg}$, dan $85 \mathrm{~kg}$. Hasil pengukuran tegangan tersebut dapat dilihat pada Tabel 2.

Tabel 2. Pengujian tegangan 35 keping piezoelektrik tersusun secara paralel tanpa beban dengan pemberian 10 kali pijakan.

\begin{tabular}{ccccc}
\hline $\begin{array}{c}\text { Berat } \\
\text { badan }\end{array}$ & Piezoelektrik & $\begin{array}{c}\text { Jumlah } \\
\text { Pijakan }\end{array}$ & Waktu & Tegangan \\
\hline $55 \mathrm{~kg}$ & 35 keping & $10 \mathrm{kali}$ & 12 detik & $3,54 \mathrm{VDC}$ \\
$60 \mathrm{~kg}$ & 35 keping & $10 \mathrm{kali}$ & 12 detik & $4,80 \mathrm{VDC}$ \\
$75 \mathrm{~kg}$ & $35 \mathrm{keping}$ & $10 \mathrm{kali}$ & $12 \mathrm{detik}$ & $5,21 \mathrm{VDC}$ \\
$85 \mathrm{~kg}$ & $35 \mathrm{keping}$ & $10 \mathrm{kali}$ & $12 \mathrm{detik}$ & $6,08 \mathrm{VDC}$ \\
\hline
\end{tabular}


Dari data Tabel 2 dapat disimpulkan, bahwa nilai tegangan yang diukur berbeda pada setiap percobaan karena dengan semakin berat beban manusia sewaktu menginjak lantai piezoelektrik yang dirangkai secara paralel maka nantinya akan meningkatkan nilai arus dibanding dengan nilai tegangan yang didapat.

\subsection{Pengujian Tegangan Dengan Berbeban dan Penyearah}

Pengukuran output tegangan 35 keping piezoelektrik tersusun secara paralel melalui pemberian penekanan yang sama dengan berat tubuh manusia bervariasi dari $55 \mathrm{~kg}, 60 \mathrm{~kg}, 75 \mathrm{~kg}$, dan $85 \mathrm{~kg}$ menggunakan beban lampu LED 2,5 volt dan terbaca arus yang keluar pada alat ukur. Hasil pengukuran tegangan tersebut dapat dilihat pada Tabel 3 .

Tabel 3. Pengujian tegangan 35 keping piezoelektrik tersusun secara paralel dengan pijakan manusia dan berbeban.

\begin{tabular}{ccccccc}
\hline $\begin{array}{c}\text { Berat } \\
\text { badan }\end{array}$ & Piezoelektrik & Waktu & $\begin{array}{c}\text { Jumlah } \\
\text { Pijakan }\end{array}$ & $\begin{array}{c}\text { Tegangan } \\
\text { (VDC) }\end{array}$ & $\begin{array}{c}\text { Arus } \\
(\mathbf{m A})\end{array}$ & $\begin{array}{c}\text { Daya } \\
(\mathbf{m W})\end{array}$ \\
\hline $55 \mathrm{~kg}$ & $35 \mathrm{keping}$ & $21 \mathrm{detik}$ & $25 \mathrm{kali}$ & 2,15 & 0,005 & 0,02 \\
$60 \mathrm{~kg}$ & $35 \mathrm{keping}$ & $21 \mathrm{detik}$ & $25 \mathrm{kali}$ & 2,16 & 0,006 & 0,02 \\
$75 \mathrm{~kg}$ & $35 \mathrm{keping}$ & $21 \mathrm{detik}$ & $25 \mathrm{kali}$ & 2,19 & 0,010 & 0,02 \\
$85 \mathrm{~kg}$ & $35 \mathrm{keping}$ & $21 \mathrm{detik}$ & $25 \mathrm{kali}$ & 2,23 & 0,027 & 0,07 \\
\hline
\end{tabular}

Dari data Tabel 3 dapat disimpulkan, bahwa semakin berat beban manusia sewaktu menginjak lantai piezoelektrik yang dirangkai secara paralel maka nantinya akan meningkatkan nilai tegangan yang didapat.

\subsection{Pengujian Tegangan pada Kapasitor}

Pengukuran ini dilakukan pada kapasitor yang berfungsi sebagai penyimpan arus listrik yang dihasilkan piezoelektrik yang telah disearahkan. Pengukuran menggunakan multimeter digital. Kapasitor yang digunakan dengan kapasitansi $22 \mu \mathrm{F}$ dan kapasitor dengan kapasitansi $1000 \mu \mathrm{F}$. Hasil pengujian tegangan menggunakan kapasitor $22 \mu \mathrm{F}$ dapat dilihat pada Tabel 4 sedangkan hasil pengujian tegangan menggunakan kapasitor $1000 \mu \mathrm{F}$ dapat dilihat pada Tabel 5.

Tabel 4. Pengujian Tegangan pada Kapasitor $22 \mu \mathrm{F}$

\begin{tabular}{ccc}
\hline No. & Waktu & $\begin{array}{c}\text { Tegangan } \\
\text { Pada Kapasitor }\end{array}$ \\
\hline 1 & 5 detik & 4,29 Volt \\
2 & 10 detik & 6,64 Volt \\
3 & 15 detik & 8,11 Volt \\
4 & 20 detik & 8,20 Volt \\
5 & 30 detik & 8,50 Volt \\
\hline
\end{tabular}

Tabel 5 Pengujian Tegangan pada Kapasitor $1000 \mu \mathrm{F}$

\begin{tabular}{ccc}
\hline No. & Waktu & $\begin{array}{c}\text { Tegangan } \\
\text { Pada Kapasitor }\end{array}$ \\
\hline 1 & 5 detik & 0,095 Volt \\
2 & 10 detik & 0,141 Volt \\
3 & 15 detik & 0,180 Volt \\
4 & 20 detik & 0,197 Volt \\
5 & 30 detik & 0,285 Volt \\
\hline
\end{tabular}

Dari data tabel 4 dan tabel 5. dapat disimpulkan, bahwa kapasitor kapasitansi $22 \mu \mathrm{F}$ lebih cepat terisi dimana semakin banyak pijakan yang dilakukan maka akan semakin banyak juga energi listrik yang dapat disimpan pada kapasitor.

\section{KESIMPULAN}

Dari hasil penelitian yang telah dilakukan pada lantai piezoelektrik maka diperoleh kesimpulan bahwa lantai pembangkit listrik menggunakan material piezoelektrik PZT ini merupakan penghasil energi listrik berdaya rendah. Namun meski berdaya rendah, pembangkit listrik ini memiliki keunggulan karena bebas dari polusi dan didapat dari energi keseharian aktifitas manusia yang terbuang sia-sia. Banyaknya kepingan material piezoelektrik yang digunakan akan berpengaruh dengan hasil keluaran piezoelektrik, karena dapat dilihat semakin banyak kepingan yang digunakan maka semakin besar pula arus dan tegangan yang dihasilkan. Desain struktur pijakan piezoelektrik juga berpengaruh besar akan hasil yang akan di dapatkan karena ketika struktur tidak bagus saat dirancang, energi yang dihasilkan piezoelektrik tidak maksimal baik tegangan ataupun arus keluarannya. 


\section{DAFTAR PUSTAKA}

[1] Almanda, D. Dermawan, E. Diniardi, E. Syawaluddin, dan Ramadahan A.I. (2016). Pengujian Model Pezoelektrik Dengan PVDF Berdasarkan Variasi Tekanan. Jakarta

[2] Boby, K., Paul, A., Anumol, C. V., Thomas, J. A., \& Nimisha, K. K. (2014). Footstep power generation using piezo electric transducers. International Journal of Engineering and Innovative Technology (IJEIT), 3(10), 1-4.

[3] Ebrahimi, Farzad. (2013). Piezoelectric Materials and Devices-Practice And Aplications. Rijeka, Croatia.

[4] Ichwan, Yelfianhar. (2012). Rangkuman Materi Piezoelektrik. Balai pustaka. Bandung

[5] Ihsani, Zadid. (2019). Piezoelektrik, https://www.academia.edu./piezoelektrik diakses pada hari Rabu tanggal 15 Juli 2020.

[6] Jr, William R. Cook. (2010). Ferroelectric and piezoelectric materials. Ohio, Amerika serikat.

[7] Mowafiq, M. Imbarothur. Junaidi, Andi dan Purwanto, Sugeng. (2018). Lantai Pemanen Energi Listrik Menggunakan Piezolelektrik. Vol. 10, No. 2. Sekolah Tinggi Teknik PLN. Jakarta.

[8] Susilo, Deddy., Firmansyah, Eka., \& Litasari. (2014). Sistem Pemanen Energi Dengan Tranduser Piezoelektrik untuk Perangkat Daya Rendah.Vol.9. No.1., Fakulta Teknik dan Komputer. Salatiga.

[9] Teknik Elektronika. (2019). Pengertian Dioda Bridge Dan Prinsip Kerjannya, https://www.teknikelektronika.com/pengertian-dioda-bridge diakses pada hari Selasa tanggal 28 April 2020.

[10] Tichi, Jan. (2010). Introduction In Fundamental of Piezoelektrik Sensorics 1st ed. Boston : Springer Science Business Media Inc.

[11] Triwahyuni, Dona. (2011). Sintesis dan Karakteristik Bahan Piezoelektrik Dengan Metode Molten Salt. Tidak diketahui.

[12] Wang, C. W., Hsu, T. K., Wu, J. H., Cheng, J. H., Yang, C. W., \& Yeh, T. C. (2012). An Optimal Rapid EnergyStoring Design for the Stackable Piezoelectric Power Generation Devices. In Advanced Materials Research (Vol. 590, pp. 189-194). Trans Tech Publications Ltd.

[13] Widodo, F. H., Kirom, M. R., \& Qurthobi. (2017). Perancangan Sistem dan Monitoring Sumber Arus Listrik dari Lantai Piezoelektrik untuk Pengisian Baterai. Dalam Proceeding of Engineering (Vol.4, hal 1). Telkom University. Bandung.

[14] Zulkifli., Margoleno, Bayu. (2018). Rancang bangun pembangkit listrik tenaga getar dengan memanfaatkan piezoelektrik. (SNIT). Politeknik Negri Bengkalis. Riau.. 